NBER WORKING PAPER SERIES

\title{
EFFECTS OF DISEASE TYPE AND LATENCY ON THE VALUE OF MORTALITY RISK
}

\author{
James K. Hammitt \\ Jin-Tan Liu \\ Working Paper 10012 \\ http://www.nber.org/papers/w10012 \\ NATIONAL BUREAU OF ECONOMIC RESEARCH \\ 1050 Massachusetts Avenue \\ Cambridge, MA 02138 \\ October 2003
}

The survey instrument was developed with support from the US Environmental Protection Agency (CX827776-01-0). Survey administration was funded by the Taiwan National Science Council (NSC90-2415H-002-030). We thank John Bennett, Maureen Cropper, John Graham, Chris Leggett, John Morrall, Kip Viscusi, the anonymous reviewers, and participants at the 2002 NBER Summer Institute for helpful comments. The views expressed herein are those of the authors and are not necessarily those of the National Bureau of Economic Research.

(C)2003 by James K. Hammitt and Jin-Tan Liu. All rights reserved. Short sections of text, not to exceed two paragraphs, may be quoted without explicit permission provided that full credit, including (C notice, is given to the source. 
Effects of Disease Type and Latency on the Value of Mortality Risk

James K. Hammitt and Jin-Tan Liu

NBER Working Paper No. 10012

October 2003

JEL No. I18, D18, D69, D81, J17

\section{ABSTRACT}

We evaluate the effects of disease type and latency on willingness to pay (WTP) to reduce environmental risks of chronic, degenerative disease. Using contingent-valuation data collected from approximately 1,200 respondents in Taiwan, we find that WTP declines with latency between exposure to environmental contaminants and manifestation of any resulting disease, at a 1.5 percent annual rate for a 20 year latency period. WTP to reduce the risk of cancer is estimated to be about one-third larger than WTP to reduce risk of a similar chronic, degenerative disease. The value of risk reduction also depends on the affected organ, environmental pathway, or payment mechanism: estimated WTP to reduce the risk of lung disease due to industrial air pollution is twice as large as WTP to reduce the risk of liver disease due to contaminated drinking water.

James K. Hammitt

Harvard School of Public Health

718 Huntington Avenue

Boston, MA 02115-5924

jkh2@hsph.harvard.edu

Jin-Tan Liu

Department of Economics

National Taiwan University

21 Hsu-Chow Road

Taipei (100), Taiwan

and NBER

liujt@ccms.ntu.edu.tw 


\section{Introduction}

Many environmental regulations are directed toward reducing risks of cancer and other disease. Yet most of the empirical literature on valuing health risk relies on estimates of the compensating wage differentials that workers receive for bearing risks of fatal injury in the workplace (Viscusi, 1993). The applicability of these wage-differential estimates to changes in environmental health risks is uncertain. Environmentally-induced cancer and other diseases differ from occupational fatal injuries in several dimensions that may affect preferences. Two that may be of particular importance are (1) the latency period between exposure to the hazardous condition and the manifestation of adverse health effects, and (2) dread or other factors that lead to greater fear of cancer than of other causes of fatality (Revesz, 1999; Sunstein, 1997). In addition, reflecting the great public attention given to cancer, there may be differences in concern about cancer and other degenerative, fatal diseases that can be caused by exposure to environmental contaminants.

We use contingent valuation $(\mathrm{CV})$ to test for effects of disease type and latency on individual willingness to pay (WTP) to reduce risks of developing a fatal cancer or other chronic, degenerative disease through exposure to environmental pollution. Because the consequences of developing cancer are more similar to those of other fatal diseases than they are to acute trauma in a workplace or other accident, our estimates of the effect of disease type on WTP may understate any difference in WTP between cancer and trauma. Data were collected from 1,248 respondents in Taiwan. We find that WTP declines with the latency period between exposure to environmental contaminants and manifestation of any resulting disease, and that WTP depends on the affected organ, environmental pathway, or payment mechanism. Our results also suggest the existence of a cancer premium, although the effect is not quite statistically significant in our preferred model specification.

In the following section, we provide an overview of the economic theory and previous empirical results concerning the effects of disease type and latency on willingness to pay for reductions in mortality risk. The CV survey instrument and sample population are described in Section 3. Section 4 describes the regression model used to 
describe the dependence of WTP on characteristics of the risk and of the respondent. Regression-model estimates suggest that WTP declines with the latency period between exposure to the environmental contaminant and manifestation of the disease, by about one-fourth over a 20 year latency period. WTP to reduce risk of cancer is estimated as about one-third larger than WTP to reduce the risk of an alternative degenerative and fatal disease. In addition, we find that WTP depends on the affected organ, environmental medium, or payment mechanism: estimated willingness to pay higher prices of consumer goods to reduce the risk of lung disease from air pollution is about twice as large as estimated willingness to pay higher water-utility rates to reduce the risk of liver disease from contaminated drinking water. Conclusions are in Section 5.

\section{Economic Theory of WTP to Reduce Mortality Risk}

The economic approach to valuing mortality risk was developed by Drèze (1962), Schelling (1968), and Jones-Lee (1974). The individual's rate of tradeoff between wealth and risk in a specified time period (e.g., the current year) is characterized by his marginal rate of substitution between survival probability s and wealth or income $\mathrm{w}$. The marginal

rate of substitution $-\frac{d w}{d s}$ (holding utility constant) is called the "value per statistical life" (VSL).

VSL is not a universal constant but varies by individual and circumstance. The standard economic model of preferences for wealth and mortality risk (Drèze, 1962; Jones-Lee, 1974; Weinstein et al., 1980) assumes that an individual's welfare can be represented as

$$
\mathrm{EU}(\mathrm{s}, \mathrm{w})=\mathrm{s} \mathrm{u}_{\mathrm{a}}(\mathrm{w})+(1-\mathrm{s}) \mathrm{u}_{\mathrm{d}}(\mathrm{w})
$$

where $s$ is the individual's chance of surviving the current period and $u_{a}(w)$ and $u_{d}(w)$ represent his indirect utility as a function of wealth conditional on surviving and not surviving the period, respectively. The function $\mathrm{u}_{\mathrm{d}}(\bullet)$ incorporates the individual's preferences for bequests and can incorporate any financial consequences of dying (such as medical bills or life-insurance benefits). In this one-period model, wealth and income are treated as equivalent, but the difference between them can be important in multiperiod models. 
The individual's VSL is derived by differentiating equation (1) holding expected utility constant to obtain

$$
V S L=-\frac{d w}{d s}=\frac{u_{a}(w)-u_{d}(w)}{s u_{a}^{\prime}(w)+(1-s) u_{d}^{\prime}(w)}=\frac{\Delta u(w)}{E u^{\prime}(w)}
$$

where prime indicates first derivative. The numerator in equation (2) is the difference in utility between surviving and dying in the current period. The denominator is the expected marginal utility of wealth, i.e., the utility associated with additional wealth conditional on surviving and dying in the period weighted by the probabilities of these events. Assuming that survival is preferred to death and that greater wealth is preferred to less, both numerator and denominator are positive and so VSL is positive. If the marginal utility of wealth is non-negative, and greater in the event of survival than death (i.e., $u_{a}^{\prime}(w)>u_{d}^{\prime}(w) \geq 0$ ), then VSL decreases in survival probability s. Weak risk aversion with respect to wealth, conditional on survival and on death (i.e., $u_{a} " \leq 0, u_{d} " \leq 0$ ), is a sufficient condition for VSL to increase with wealth.

\section{Accounting for Latency}

In equation (2), VSL is defined in terms of wealth and mortality risk in a single period. Many environmental health risks are characterized by a latency period between the time an individual is exposed to an agent and the time when he may die from its toxic effect. Since preventive measures must be undertaken before the exposure occurs, there is a need to determine WTP now to reduce the risk of fatality in a future period. We focus on WTP for a temporary risk reduction, i.e., one that reduces mortality risk in a single period. WTP to reduce mortality risk in multiple future periods (e.g., by permanently reducing exposure to an environmental toxicant) can be calculated by summing WTP to reduce risk in each of the future periods (Johannesson et al., 1997).

Intuitively, one might expect that WTP to reduce a latent risk must be smaller than WTP to reduce a current risk by the same amount, since reducing a current risk increases the chance of surviving both current and future periods while reducing a future risk increases only the chance of surviving the future periods. This intuition is misleading. An earlier risk reduction does not necessarily stochastically dominate a later risk reduction, and so preferences between reducing current and latent risks will depend 
on the utility associated with different periods of life. WTP to reduce future mortality risk can be less than, equal to, or greater than WTP to reduce current risk by the same amount.

Consider a multi-period model where the probabilities of surviving the first and second periods, conditional on being alive at the beginning of these periods, are $s_{1}$ and $s_{2}$, respectively. The probability of surviving at least one period is $s_{1}$ and the probability of surviving at least two periods is $\mathrm{s}_{1} \bullet \mathrm{s}_{2}$. Reducing the first-period risk by an amount $\Delta$ increases these probabilities to $\left(\mathrm{s}_{1}+\Delta\right)$ and $\left(\mathrm{s}_{1}+\Delta\right) \mathrm{s}_{2}$, respectively. Reducing the second-period risk by $\Delta$ does not affect the probability of surviving at least one period but increases the probability of surviving at least two periods to $\mathrm{s}_{1}\left(\mathrm{~s}_{2}+\Delta\right)$. Comparing the probabilities of surviving at least one period, the first-period risk reduction is clearly preferred. In contrast, the probability of surviving at least two periods is larger for the second-period risk reduction than for the first-period risk reduction if $\mathrm{s}_{2}<\mathrm{s}_{1}$. Hence the earlier risk reduction will stochastically dominate the later risk reduction only when $s_{2} \geq$ $\mathrm{S}_{1} \cdot{ }^{1}$

Since conditional mortality rates tend to rise with age, $s_{2}$ is usually smaller than $s_{1}$ (for periods of equal duration). In this case, reducing current mortality risk does not stochastically dominate reducing future mortality risk by the same amount, and so WTP to reduce current and future risks will depend on the utility associated with surviving for different lengths of time. Typically, WTP to reduce a current risk will exceed WTP to reduce a latent risk. However, if the utility of short-term survival is small compared with the utility of longer-term survival, future risk reduction may be preferred to current risk reduction and WTP to reduce risk can increase with latency. For example, consider an individual suffering a painful illness in period 1 who will recover to full health at the end of period 2. If the illness is so painful that he would prefer to die rather than to live the rest of his life with the illness, the only benefit of surviving period 1 is that it increases his chance of surviving to the end of period 2 , when he will recover. If $s_{2}<s_{1}$, then

\footnotetext{
${ }^{1}$ In the case of permanent risk reductions (i.e., those that increase the survival probability by $\Delta$ in every period after the end of any latency period), an intervention with a shorter latency period increases the chance of surviving for every number of periods, is stochastically dominant, and will be associated with a larger WTP.
} 
increasing $\mathrm{s}_{2}$ will enhance his probability of surviving until he recovers by more than increasing $\mathrm{s}_{1}$, and so his WTP will be larger for the future than for the current risk reduction.

Standard economic theory suggests that the appropriate procedure to account for latency is to value the risk change using the VSL representing the individual's value when the harmful effects of the risk manifest, and to adjust for the time-value of money before then (Cropper and Sussman, 1990; Cropper and Portney, 1990; Johannesson et al., 1997). Consider a simple two-period model in which the individual seeks to maximize his expected present value of utility

$$
\mathrm{EU}=\mathrm{s}_{1} \mathrm{u}_{1}\left(\mathrm{c}_{1}\right)+\mathrm{s}_{1} \mathrm{~s}_{2} \mathrm{u}_{2}\left(\mathrm{c}_{2}\right)
$$

subject to a budget constraint

$$
c_{1}+\frac{1}{1+r} c_{2}=B
$$

In equation (3), $s_{1}$ and $s_{2}$ are the probabilities of surviving periods 1 and 2 , conditional on being alive at the start of each period. The functions $u_{j}\left(c_{j}\right), j=1,2$, represent the utility in period $\mathrm{j}$ of consumption $\mathrm{c}_{\mathrm{j}}$. They are assumed to be increasing and weakly concave $\left(\mathrm{u}_{\mathrm{j}}^{\prime}>\right.$ $\left.0, u_{j}^{\prime \prime} \leq 0\right)$. Any effects of age, duration of period, or preferences for current relative to future utility may be incorporated in the within-period utility functions. For simplicity, the marginal utility of a bequest is assumed to be zero. ${ }^{2}$

The first-order condition for optimizing consumption between periods is

$$
\frac{u_{1}^{\prime}\left(c_{1}\right)}{u_{2}^{\prime}\left(c_{2}\right)}=s_{2}(1+r) \text {. }
$$

As written, the budget constraint (4) implies the individual can save or borrow against lifetime wealth B at a constant consumption-discount rate $r$. The first-order condition (5) is necessary for optimization if the individual can save and borrow at least small amounts at rate $r$. The rate may depend on the individual's survival probabilities. With perfect contingent-claim markets, the individual can transfer consumption between periods at a rate satisfying $(1+r)=(1+\rho) / s_{1}$, where $\rho$ is a risk-free interest rate and no payment is

\footnotetext{
${ }^{2}$ Other life-cycle models (e.g., Shepard and Zeckhauser, 1984; Rosen, 1988; Ng, 1992) also assume a zero marginal utility of bequest, which avoids the question of how the utility of a bequest depends on when the individual dies.
} 
made in the second period if the individual dies in the first period. ${ }^{3}$ For secured loans, the individual may borrow or save at the risk-free interest rate, which is independent of his mortality risk.

The marginal rate of substitution between period $\mathrm{j}$ consumption and period $\mathrm{k}$ survival probability may be denoted $\mathrm{VSL}_{\mathrm{j}, \mathrm{k}}$. Differentiating equation (3), holding expected utility constant, implies that current WTP to reduce current mortality risk is given by

$$
V S L_{1,1}=-\frac{d c_{1}}{d s_{1}}=\frac{u_{1}\left(c_{1}\right)+s_{2} u_{2}\left(c_{2}\right)}{s_{1} u_{1}^{\prime}\left(c_{1}\right)}
$$

current WTP to reduce future risk is given by

$$
V S L_{1,2}=-\frac{d c_{1}}{d s_{2}}=\frac{u_{2}\left(c_{2}\right)}{u_{1}^{\prime}\left(c_{1}\right)}
$$

and future WTP to reduce future risk is given by

$$
V S L_{2,2}=-\frac{d c_{2}}{d s_{2}}=\frac{u_{2}\left(c_{2}\right)}{s_{2} u_{2}^{\prime}\left(c_{2}\right)} \text {. }
$$

Current WTP to reduce future mortality risk is simply the present value of future WTP to reduce future risk. Combining equations (7) and (8),

$$
V S L_{1,2}=\frac{S_{2} u_{2}^{\prime}\left(c_{2}\right)}{u_{1}^{\prime}\left(c_{1}\right)} V S L_{2,2}=\frac{1}{1+r} V S L_{2,2},
$$

where the second equality is obtained by substitution from the first-order condition (5).

The effect of latency on WTP for risk reduction depends on how the rate of substitution between contemporaneous consumption and survival probability changes over time. If the rate of substitution increases sufficiently over time (i.e., if $\mathrm{VSL}_{2,2}>(1+$ r) $\mathrm{VSL}_{1,1}$ ), then WTP to reduce a latent risk will exceed WTP for an equally large reduction in current risk. To determine the conditions under which latency increases WTP, subtract equation (7) from equation (6) to obtain

$$
V S L_{1,1}-V S L_{1,2}=\frac{u_{1}\left(c_{1}\right)+\left[s_{2}-s_{1}\right] u_{2}\left(c_{2}\right)}{s_{1} u_{1}^{\prime}\left(c_{1}\right)} .
$$

\footnotetext{
${ }^{3}$ If the individual dies in the first period, his estate is not required to repay any loans and forfeits any savings.
} 
WTP to reduce a latent risk exceeds WTP to reduce a similar current risk (i.e., VSL $_{1,2}>$ $\mathrm{VSL}_{1,1}$ ) if and only if

$$
\frac{u_{1}\left(c_{1}\right)}{u_{2}\left(c_{2}\right)}<s_{1}-s_{2} \text {. }
$$

If the two periods are of equal duration, the right-hand side of equation (11) is likely to be positive, since hazard rates typically increase with age. If so, and if first-period utility is sufficiently small relative to second-period utility, condition (11) may be satisfied. Such a result seems unlikely but cannot be ruled out without further restrictions on the utility functions. $^{4}$

Note that current WTP to reduce a latent risk (equations (7) and (9)) does not incorporate any component related to anxiety about whether the latent risk will prove fatal. While such a component might be important in assessing WTP to avoid exposure to a specific hazard (such as the risk of getting smallpox from vaccination), it seems unlikely that the degree of anxiety about the potential harm from exposure to continuing environmental risks is sensitive to small changes in the magnitude of the risk that do not eliminate the risk entirely.

Equation (9) shows that WTP to reduce a latent risk depends on the individual's future WTP to reduce the future risk, i.e., his future VSL. The difference between an individual's current and future VSL depends on two factors: he will be older, and the date will be later. Age affects VSL because the individual's life expectancy, health, earnings, opportunities for spending on other goods, and other factors vary with stage of the life cycle. Time or date affect VSL through secular changes in productivity, the availability of medical and other technologies for investing in longevity, and other factors. A number of theoretical and empirical studies have examined the effects of age on VSL, but the effect of date has received little attention. Because of secular changes in productivity and other factors, the VSL at age 70 of a current 30 year old is unlikely to be equal to the current VSL of a current 70 year old.

\footnotetext{
${ }^{4}$ If the within-period utility functions are identical, $\mathrm{u}_{1}(\bullet)=\mathrm{u}_{2}(\bullet)$, then WTP to reduce mortality risk unambiguously declines with latency.
} 
The effect of age has been examined in theoretical models and, to a limited extent, by empirical studies. Theoretical models similar to equations (3) and (4) but including many periods (e.g., Shepard and Zeckhauser, 1984; Rosen, 1988; Ng, 1992) suggest that two factors influence the life-cycle pattern of VSL. First, the number of future life years at risk declines as one ages, so the benefit of surviving the current period (the numerator in equation (2)) declines. Second, the opportunity cost of spending on risk reduction (the denominator in equation (2)) also declines with age as savings accumulate, the investment horizon approaches, and the survival probability s decreases. The net effect of these changes may cause VSL to fall or rise with age (Ng, 1992; Hammitt, 2000a).

In models that assume an individual can borrow against future earnings, VSL typically declines with age (e.g., Rosen, 1988). Shepard and Zeckhauser (1984) calculate that VSL for a typical American worker falls by a factor of three from age 25 to age 75 . If individuals can save but not borrow, VSL rises in early years as the individual's savings (and earnings) increase before it ultimately declines. In this case, Shepard and Zeckhauser find that VSL peaks near age 40 and is less than half as large at ages 20 and 65.

$\mathrm{Ng}$ (1992) argues that the rate at which individuals discount their future utility is likely to be smaller than the rate of return to financial assets, whereas Shepard and Zeckhauser (1984) assume these rates are equal. If the utility-discount rate is smaller than the rate of return, individuals should save more when they are young and consume more when old. Under these conditions, VSL may not peak until age 60 or so (Ng, 1992). Even if individuals discount future utility at the rate of return, younger people who are prudent ${ }^{5}$ might be anticipated to save more, and spend less on reducing mortality risk, because of the greater range of future financial contingencies they face.

Empirical evidence of the effect of age on VSL is mixed, with most results suggesting age has only a modest effect. Many studies that do not focus on the effect of age nevertheless include it as one of several covariates in a regression model explaining

\footnotetext{
${ }^{5}$ An individual is prudent if financial risk increases his expected marginal utility of wealth, which requires that the third derivative of his utility function for wealth is positive (Kimball, 1990).
} 
WTP for risk reduction. The results of these studies are somewhat contradictory, with several finding VSL increases with age (e.g., Gerking et al., 1988; Lee et al., 1997) and others finding VSL decreases with age (e.g., Buzby et al., 1995; Hammitt and Graham, 1999; Corso et al., 2001). Other studies find that VSL first rises then falls with age, peaking in middle age (Jones-Lee et al., 1985; Johannesson et al., 1997).

Viscusi and co-authors find that VSL is proportional to the present value of future life years. The implied effect of life expectancy on VSL is sensitive to the estimated discount rate, which varies from about 1 to 17 percent per year. For rates of 10 percent and above (Moore and Viscusi, 1988, 1990b; Viscusi and Moore, 1989; Dreyfus and Viscusi, 1995), tripling future longevity from 20 to 60 years increases VSL by no more than 17 percent. For a 1 to 2 percent discount rate (Moore and Viscusi, 1990a, 1990b), the same change in longevity increases VSL by a factor of 2.0 to 2.5.

Three recent empirical studies are specifically directed toward estimating the effect of age on VSL. Krupnick et al. (2002) conducted a CV study of WTP for a hypothetical intervention that would reduce the respondent's risk of dying in the next 10 years, restricting their sample to Canadian respondents aged 40 years and older. Krupnick et al. estimated that VSL is roughly constant for ages $40-69$, and is about 30 percent smaller for individuals aged 70 and older. Using a similar survey instrument with American respondents, Alberini et al. (2002) found no statistically significant effect of age, although their point estimate suggests that VSL is about 20 percent smaller for respondents older than 70 than for younger respondents. Smith et al. (2001) estimated compensating-wage differential estimates using data from the Health and Retirement Survey. Their estimates of VSL for individuals aged $51-65$ are not sensitive to age and are comparable to standard estimates for younger populations.

The effect of calendar time on VSL has received relatively little attention in the literature, except to observe that if income grows over time, VSL might be expected to increase. ${ }^{6}$ However, anticipated increases in income over the lifecycle may not affect VSL if WTP for current mortality-risk reduction is based on expected or "permanent"

\footnotetext{
${ }^{6}$ In evaluating restrictions on CFCs to protect stratospheric ozone, for example, the US Environmental Protection Agency assumed that increases in income would cause VSL to grow at annual rates of $0.85-3.4$ percent (EPA, 1987).
} 
income. In this case, anticipated secular earnings growth should be incorporated in current VSL. Changes in diet, medical technologies, environmental and other factors that influence the survival curve and the costs of increasing survival probabilities may also affect VSL, as they affect both the utility gain and the expected marginal cost of spending (the numerator and denominator of equation (2)). If VSL depends on current rather than permanent income, the effect changing income can be estimated using estimates of the economic growth rate and the income elasticity.

Several studies have attempted to empirically estimate the effects of both calendar time and age on the benefits of public life-saving programs, by asking respondents to choose between hypothetical lifesaving programs that protect people of different ages or at different dates. These results do not necessarily reflect individual WTP to reduce different risks to oneself, since survey respondents are unlikely to compare programs solely in terms of their own private benefits. Horowitz and Carson (1990) estimated that respondents discount for calendar time at annual rates of 5-12 percent for delays of three to five years. Cropper et al. (1994) estimated a somewhat larger rate of 17 percent for five years, falling to $4-5$ percent for delays of $50-100$ years. Cropper et al. also asked respondents about programs to save people of different ages. Their results suggest that respondents prefer to protect people in young middle age. Lives of 30 year olds are valued about 11 times more highly than lives of 60 year olds. For comparison, lives of 20 and 40 year olds are valued as equal to about eight and seven 60 year olds, respectively. These results are not sensitive to the age of the respondent.

Subramanian and Cropper (2000) asked respondents to choose between different public programs to reduce health risks, and then asked how much more effective (in terms of lives saved) the less preferred program would need to be to make the respondent indifferent between programs. In each case, the risks concerned the same health endpoint but differed in delay until benefits would be achieved, voluntariness, controllability, and other factors. Using a multivariate regression to control for the effects of various factors, Subramanian and Cropper found that respondents discounted for delay. They estimated a marginal rate of substitution of -0.15 , which implies that a 1.5 percent increase in the number of lives saved would compensate for a 10 percent increase in delay. 
To summarize, the effect of latency on WTP to reduce own mortality risk is uncertain. In theory, latency may increase or decrease WTP depending on whether individual VSL increases enough to offset the individual's consumption discount rate. Empirical studies have not resolved this ambiguity.

\section{Magnitude of Cancer Premium}

The value of preventing a fatal cancer is often considered to be greater than the value of preventing a fatal trauma in a workplace or transportation accident (Revesz, 1999; Sunstein, 1997). Cancer is also frequently viewed as more threatening than other degenerative conditions, such as heart disease (Jones-Lee et al., 1985).

There are a number of differences between cancer and trauma fatalities that might affect relative WTP to reduce each risk, including the often protracted suffering from cancer before death and the knowledge with cancer that one's condition will deteriorate and lead to death. It is not obvious that WTP to reduce cancer risk exceeds WTP to reduce accident risk, however, since dying of cancer and other degenerative diseases offers some benefits relative to dying in a fatal accident, such as the possibility of preparing for death by reconciling with family or putting financial affairs in order. Despite the plausibility that there may be a cancer premium, empirical support is limited. We are aware of no studies that compare individual WTP to reduce one's own risk of cancer and other fatal disease, although several studies provide some information about the relative value of reducing risks of cancer and of fatal trauma.

Jones-Lee et al. (1985) asked respondents to choose between public programs that would reduce the number of people dying in the next year by 100 from one of three causes (motor-vehicle crashes, heart disease, and cancer), and to indicate how much they would voluntarily contribute to reducing the number of deaths from the cause they selected. A large majority of respondents ( 76 percent) chose to reduce cancer deaths and the mean voluntary contribution was larger for cancer than for the other causes. If the mean contributions are interpreted as estimates of WTP to reduce own risk, the implied VSLs are $£ 23$ million for cancer, $£ 13$ million for heart disease, and $£ 7$ million for motorvehicle accidents. 
Mendeloff and Kaplan (1989) asked several sets of survey respondents to indicate the appropriate relative levels of public spending per life saved from various causes. Their sample of 38 non-elderly adults valued preventing cancer deaths due to workplace chemical exposures with a 30 year latency period as about twice as important as preventing trauma deaths due to workplace (construction) falls, and also valued preventing the cancer deaths as more valuable than preventing trauma deaths to younger people that could be prevented by improved road engineering (installation of median barriers and removal of roadside obstacles). Their sample of 190 college undergraduates reported a similar preference ordering, although the relative values differ less. In contrast, their samples of 18 retirees and of 35 undergraduates ranked the cancer deaths as similar to the construction and road-accident deaths.

McDaniels et al. (1992) estimated WTP for programs to reduce a wide range of health risks using a CV study with 55 respondents. The programs were described as public goods that would reduce risks to the relevant populations, not only to the respondent. The authors also elicited risk-perception variables, such as dread. They found that WTP to reduce risk was positively associated with dread.

Savage (1993) asked survey respondents to allocate a hypothetical $\$ 100$ contribution to research intended to reduce risks of stomach cancer, household fires, commercial-airplane accidents, and automobile accidents. He found that respondents would allocate the largest amount to stomach cancer (\$47) with much smaller amounts $(\$ 15-\$ 21)$ to the other risks. Although this study suggests greater WTP to reduce cancer risks, it does not measure individual WTP to reduce own risk. The value of research on methods to reduce risk of cancer (or the other fatality risks) depends on the probability that the research will identify interventions to reduce the risk, the magnitude of the risk reduction produced by the interventions, and the cost of implementing them. None of these parameters were specified, and so one cannot know what assumptions respondents made about them. In addition, the pattern of responses seems inconsistent with a measurement of WTP to reduce risk. Because the marginal efficacy of research spending is unlikely to decline significantly with a $\$ 100$ increase, the optimal response is likely to be allocating all $\$ 100$ to whichever risk the respondent believes will benefit most. 
Magat et al. (1996) used a risk-risk survey to elicit preferences for reductions in the risk of fatal automobile accidents and three chronic diseases: terminal lymph cancer, curable lymph cancer, and non-fatal nerve disease. The latency periods for the diseases were not specified in the survey instrument. The median respondent was indifferent between equal reductions in the probability of terminal lymph cancer and of fatal automobile accident, suggesting that there is no cancer premium or that any cancer premium is offset by an assumed difference in latency. The losses in utility due to curable lymph cancer and non-fatal nerve disease were estimated as 58 percent and 40 percent as large as the loss from a fatal automobile accident, respectively, which suggests that the utility loss associated with morbidity is 45 percent larger for lymph cancer than for nerve disease.

\section{Contingent Valuation Survey}

To estimate the effects of disease type and latency on WTP to reduce mortality risk, we conducted a contingent valuation (CV) survey. This section describes the survey instrument and sampling plan.

\section{Survey Instrument}

Respondents were questioned about their WTP to protect everyone in their household from each of four environmental health risks. The valuation questions are provided in the Appendix.

The risks vary among respondents and differ with respect to whether the disease is latent or acute, cancer or non-cancer, and whether it affects the lung or the liver. To enhance credibility of the scenarios, the risks associated with liver disease are described as being produced by a contaminant in the water supply, and the risks associated with lung disease are attributed to industrial air pollution. The payment mechanism differs accordingly. In the liver case, respondents are asked about their willingness to pay higher water bills to cover the cost of additional treatment at the water utility. In the lung case, respondents are asked about their willingness to pay higher prices for consumer goods. Because the affected organ, environmental pathway, and payment mechanism are confounded in our design, we cannot distinguish their effects on WTP. In addition, 
because the interventions reduce risks to other community members in addition to those in the respondent's household, estimated WTP may include some component of altruism.

The risk reduction is described as an intervention to reduce current exposure to environmental contaminants. In the case of acute disease, respondents are told that if someone in their household develops the stated disease, symptoms will begin within a few months and they will live only about two to three years longer. In the latent case, they are told the person will not know if he or she was sufficiently exposed to develop the disease until symptoms begin about 20 years in the future. After developing symptoms, the prognosis is identical to the acute case. The symptom description is terse but includes what are believed to be the most salient aspects of the diseases. The description is identical for all four diseases (cancer/non-cancer, liver/lung).

The magnitude of the risk reduction is also varied (either 2 per 100,000 or 8 per 100,000 per year). Under conventional economic theory, WTP for a small reduction in mortality risk is nearly linear in the magnitude of the risk reduction. The sensitivity of estimated WTP to magnitude of risk reduction can be used as a diagnostic test of the performance of the survey instrument (Hammitt and Graham, 1999; Hammitt, 2000b; Corso et al., 2001).

A split-sample design is employed in which respondents are randomly assigned to one of eight groups. All respondents are presented with four WTP questions, with the specific risk reductions varied among the sub-samples as detailed in Table A-1 (in the Appendix).

WTP is elicited using double-bounded binary-choice questions. Each respondent is randomly assigned to one of five initial bid values (NT\$50, 100, 200, 300, and 500). ${ }^{7}$ These amounts represent additional monthly expenditures. The values are based on responses to open-ended questions in two survey pretests. There is one follow-up question, where the bid is equal to twice the initial bid if the respondent indicates he would be willing to pay the initial amount, and equal to half the initial bid otherwise. Each respondent receives the same initial bid for the first two questions (which pertain to a common organ/environmental pathway) and a different initial bid for the second two

\footnotetext{
${ }^{7}$ The exchange rate was 34.5 NT\$ per US\$ in May 2001.
} 
questions (which pertain to the other organ/environmental pathway). Discrete-choice questions are often preferred to open-ended questions because they appear to be easier for respondents to answer. The referendum format is incentive-compatible and was recommended by the NOAA panel (Arrow et al., 1993). The double-bounded formulation is more efficient than a single-bounded dichotomous-choice formulation (Hanemann et al., 1991).

\section{Survey Sample}

The survey was conducted in May 2001 using random-digit-dial computerassisted telephone interviewing in Taiwan. The sample was restricted to individuals aged 16 years and older with earned income and residing in Taipei city or county, Taoyuan county, or Kaohsiung city or county. In total, 1,248 interviews were completed. The regions were chosen to include areas with relatively severe (Taoyuan, Kaohsiung) and relatively mild (Taipei) levels of industrial pollution.

Table 1 reports the definitions of all variables together with the sample means and standard deviations. The sample statistics are consistent with expectations, given the sampling plan. The respondents' mean age is 39 years, with a range of 16 to 70 . Threequarters of the respondents are married and 55 percent are male. Almost one-quarter have obtained a college degree. The mean income is about US $\$ 14,000$ per year. About 60 percent describe their health as excellent or very good (alternative choices are good, fair, and poor). More than one-quarter of the respondents are current smokers, and about onesixth report they suffer from respiratory illness. About two-thirds routinely use seatbelts when traveling in an automobile.

\section{Results}

WTP is modeled as a function of health-risk attributes, the respondent's socioeconomic characteristics, and variables characterizing risk attitudes. Regression models are estimated using the maximum-likelihood method under the assumption that WTP is lognormally distributed. ${ }^{8}$ We include in the sample only the response to one randomly

\footnotetext{
${ }^{8}$ Using a $\chi^{2}$ test we find that the lognormal model provides a better fit than the Weibull, exponential, and log-logistic models. The estimated coefficients using alternative distributions have the same signs. We also
} 
selected question per respondent, so the observations are independent. This section reports estimates of how WTP to reduce health risks depends on the characteristics of those risks as well as on respondents' personal characteristics.

\section{Effects of Health-Risk Characteristics on WTP}

To determine how WTP depends on the characteristics of the health risks, we estimate a regression that includes only dummy variables for the various risk characteristics: cancer/non-cancer, latent/acute, liver/lung, and magnitude of risk reduction. The results are shown in column 1 of Table 2 .

The estimated coefficient of the cancer variable is positive and almost significant (the p-value is 0.12 ). The point estimate suggests that WTP to reduce the risk of cancer is one-third larger than WTP to reduce the risk of an alternative disease. The coefficients of the latent and liver variables are both negative and statistically significant at the 10 percent and 1 percent levels, respectively. WTP to reduce the latent risk is estimated as about one-fourth smaller then WTP to reduce the acute risk, which implies respondents discount for latency at about 1.5 percent per year. WTP to reduce the risk of liver disease from water pollution is estimated to be only half as large as WTP to reduce the risk of lung disease from air pollution. ${ }^{9}$

The estimated coefficient on risk magnitude allows us to reject the hypothesis that WTP is insensitive to the magnitude of risk reduction, but the magnitude of the coefficient is much smaller than the value $(\log (4) \approx 1.4)$ required for estimated WTP to be proportional to magnitude of risk reduction. This result - that WTP is sensitive to risk magnitude, but less than proportionate - is consistent with nearly all previous CV studies of health-risk reduction (Hammitt and Graham, 1999; Krupnick et al., 2002) and may

evaluate the Weibull and lognormal results using a likelihood-ratio test. We can reject the Weibull distribution in favor of an alternative generalized Gamma distribution, but cannot reject the lognormal distribution against the alternative generalized Gamma distribution. As sensitivity analysis, we describe the Weibull results below.

${ }^{9}$ The Weibull model yields qualitatively similar results, although the p-values differ. The coefficient on cancer is significant at the 1 percent level and implies WTP to reduce cancer risk is 57 percent larger than WTP to reduce risk of a similar non-cancer disease. The coefficient on latency has a p-value of 0.11 and the point estimate suggests WTP to reduce the latent risk is 20 percent smaller than WTP to reduce the acute risk. WTP to reduce the risk of liver disease is highly significant and estimated as about half as large as WTP to reduce the risk of lung disease. 
reflect inadequate communication of the quantitative risk reduction to survey respondents (Corso et al., 2001).

To control for question-order effects, we add three question-dummy variables (Q1 - Q3) to the variables describing the risk characteristics. As shown in column 2 of Table 2, estimated WTP seems to decrease with question order, although only the responses to the first and fourth questions differ significantly. This pattern suggests that respondents act as if they mentally allocate spending in response to each question and are less willing to spend on the later questions. Payne et al. (2000) found a similar effect in their study, where CV estimates of WTP for the first of five environmental goods was significantly larger than estimates of WTP for the remaining goods. Despite the statistically significant effect of question order, controlling for this factor has a negligible effect on the estimated coefficients of the risk characteristics. ${ }^{10}$

In order to identify any differences in the estimated cancer premium or latency effect with disease type or affected organ we added interaction variables to the specification reported in column 2. Interactions between Cancer and Latent, Cancer and Liver, and Latent and Liver, were entered individually and jointly. None of the coefficients on these interaction terms were significantly different from zero and their inclusion had little effect on the magnitude of the other coefficients. (Estimates of these specifications are omitted from the table.)

\section{Effects of Respondent Characteristics on WTP}

In column 3 of Table 2, we add respondent characteristics to the riskcharacteristic and question-order variables. We omit 94 observations for which personal characteristics are missing, so the sample size falls from 1,222 to 1,128 respondents.

Addition of the respondent characteristics has a minimal effect on the estimated coefficients of the risk-characteristic variables. The cancer coefficient remains close to significant (the p-value is 0.103 ) and the cancer premium is estimated as 38 percent. The coefficient on latency is significant at the 10 percent level and implies WTP is one-fourth

\footnotetext{
10 The question-order variables also have little effect on the Weibull model. The coefficients and p-values for the cancer and liver variables are nearly identical to those reported in the previous note and the coefficient on latency has a p-value of 0.04 .
} 
smaller for the latent than for the acute risk. The estimated value of reducing the risk of liver disease due to water contamination remains 50 percent smaller than WTP to reduce the risk of lung disease due to air pollution. ${ }^{11}$

Estimated WTP is significantly associated with some of the respondents' socioeconomic characteristics. The estimated income elasticity $(0.61$, standard error $=0.20)$ is comparable to estimates obtained in other studies of health risk (e.g., Jones-Lee et al., 1985; Mitchell and Carson, 1986; Liu et al., 1997; Corso et al., 2001; Mrozek and Taylor, 2002; Viscusi and Aldy, 2002). Estimated WTP declines with age at a rate of about 2.3 percent per year, and college-educated respondents are estimated to value risk reduction about 40 percent more than respondents with less education (the coefficient on college is almost significant, with a p-value of 0.106 ). In contrast, WTP is not significantly associated with the number of household members, even though the questions ask about WTP to reduce risk to everyone in the household. There is no significant association between WTP and either sex or marital status.

Several variables are included as indicators of risk attitudes, but none are statistically significant. The negative coefficient for current smokers is consistent with wage-differential studies which suggest that smokers value safety less than non-smokers (Hersch and Viscusi, 1990; Hersch and Pickton, 1995; Viscusi and Hersch, 2001). WTP is not significantly associated with use of automobile seatbelts, perceived health status, presence of respiratory disease, or with perceived air and drinking-water quality (after controlling for geographic region). Moreover, we find no significant differences in WTP associated with ethnicity or geographic region of residence.

\section{Effect of Latency}

The estimated coefficients on latency suggest that respondents discount for latency at about 1.5 percent per year. ${ }^{12}$ To evaluate this estimate, we examine its

\footnotetext{
${ }^{11}$ For the Weibull model, the cancer premium is significant at the 1 percent level and estimated as 68 percent. WTP for the latent risk is estimated to be one-fourth smaller than WTP for the acute risk and the p-value is 0.08 . The estimated WTP to reduce liver disease remains about half as large as WTP to reduce lung disease and highly significant.

12 The CV studies reported by Alberini et al. (2002) and Krupnick et al. (2002) included questions about the respondents' WTP to reduce the risk of dying in the next decade and also in the decade following the respondent's 70th birthday. Comparing these values suggests that respondents discount for latency at
} 
consistency with the theoretical result that WTP to reduce a future mortality risk depends on the individual's consumption discount rate (which may depend on his survival probability) and the change in VSL between the current and future times (equation (9)). The change in VSL depends on differences in age, health, and other factors between the current and future periods. It may also depend on changes in income, to the extent these are not incorporated in current VSL.

The proportional change in WTP for a latency period of $t$ years can be represented as

$$
\frac{W T P_{t}}{W T P_{0}}=\left(\frac{1}{1+r}\right)^{t} a_{t}(1+g)^{t \eta}
$$

where $\mathrm{WTP}_{0}$ and $\mathrm{WTP}_{\mathrm{t}}$ are the individual's current WTP to reduce mortality risk by a small amount $\Delta$ at the current time and t years in the future, respectively, $r$ is his consumption discount rate (as in equation (4)), $a_{t}$ is a factor describing how VSL depends on age, $\mathrm{g}$ is the annual income-growth rate, and $\eta$ is the income elasticity. ${ }^{13}$ From column (3) of Table 3, $\mathrm{WTP}_{20} / \mathrm{WTP}_{0}$ is estimated as 0.74 and $\mathrm{a}_{20}$ is estimated as $0.63=\mathrm{e}^{-0.023 \bullet 20}$. Since the estimated age effect reduces WTP by more than the observed discounting for latency, equation (12) implies that VSL is anticipated to increase because of increasing income (or other factors), or that the consumption discount rate is less than zero (equal to about -0.7 percent per year). Attributing the difference to anticipated income growth and using the estimated income elasticity of 0.61 , the following pairs of consumption discount rate and anticipated income-growth rate are consistent with our results: $(r=0, g$ $=0.01),(\mathrm{r}=0.03, \mathrm{~g}=0.06),(\mathrm{r}=0.05, \mathrm{~g}=0.10)$, and $(\mathrm{r}=0.10, \mathrm{~g}=0.18)$. For the smaller discount rates, the anticipated income-growth rates appear reasonable. Taiwan has experienced rapid economic growth in recent years, with real rates of 5 and 6 percent per year and individual incomes typically rise with age. In contrast, the anticipated growth rates that are associated with the larger consumption discount rates seem implausible, potentially reflecting inadequate sensitivity of estimated WTP to latency.

annual rates of 4.5 and 8 percent in the US and Canada, respectively (Maureen Cropper, personal communication, July 31, 2002).

${ }^{13}$ Moore and Viscusi (1990) present a similar equation. 


\section{Value per Statistical Life}

Table 3 reports estimates of VSL as a function of disease type, latency, and organ/environmental pathway/payment mechanism. These are calculated using the corresponding estimates of WTP from the regression models in Table 2 to predict median WTP at the sample mean of the covariates for each risk reduction, dividing by the risk reduction and average household size (4.3), then averaging over the small and large risk reductions.

Estimated VSL ranges between US\$0.5 million and US\$2.2 million. These values are substantially smaller than estimates for the US (Viscusi, 1993; Mrozek and Taylor, 2002; Viscusi and Aldy, 2002) and are comparable to previous estimates for Taiwan. Using compensating wage differentials, Liu et al. (1997) estimated a value of approximately US\$0.5 million using actuarial risk estimates for 1982 - 1986, and Liu and Hammitt (1999) estimated VSL in 1995 as US\$0.6 million (controlling for injury risk) and US\$1.2 million (not controlling for injury risk), using workers' subjective risk estimates. Using CV, Fu et al. (1999) estimated WTP per statistical case of cancer avoided by reducing pesticide residues on food in Taiwan as US\$0.6 - 1.3 million in 1995.

\section{Conclusion}

Health benefits of environmental regulations are frequently associated with reduced risks of cancer and of other degenerative and fatal diseases. To date, there is little evidence regarding the extent to which individual WTP to reduce fatal risks differs by characteristics of the risk, including the type of disease or trauma and the latency period between exposure to the hazard and fatal outcome.

In a general-population contingent-valuation study in Taiwan, we find that WTP to reduce risks of fatal cancer due to environmental pollution is larger than WTP to reduce risks of an otherwise similar degenerative disease, and that current WTP declines with the latency period between exposure to environmental contaminants and manifestation of disease. Respondents appear to discount at a rate of about 1.5 percent per year for a 20 year latency period. We also find that WTP to reduce risks of lung disease due to industrial air pollution through higher prices of consumer goods is 
substantially greater than WTP to reduce risks of liver disease due to water pollution through higher water-utility rates. Because these factors are confounded in our study design, we are unable to separately estimate the effects of differences in the affected organ (lung or liver), environmental pathway (air or drinking and bathing water), and payment mechanism (higher payments for consumer goods or higher water utility bills).

We conjecture that the estimated differences in WTP between diseases (e.g., the cancer premium and the affected organ) may be sensitive to the comprehensiveness of the information about disease symptoms and prognosis provided to survey respondents. Even though we use identical language to describe the symptoms and prognosis of the four diseases, the descriptions are brief and respondents may have believed that cancers have more severe effects on health than the other diseases, or that lung disease has more severe effects than liver disease. In future work, we intend to assess the sensitivity of the estimated differences in WTP to the level of detail with which disease symptoms are presented to respondents. We anticipate that the estimated differences will be smaller when more information about the disease characteristics is provided to respondents.

For evaluating environmental regulations, our results suggest that benefits of mortality-risk reduction should be reduced modestly to account for the latency period between exposure and manifestation of disease. They further suggest the existence of substantial differences in VSL associated with specific diseases. In particular, reductions in the risk of fatal cancer may be more valuable than comparable reductions in risks of other fatal, degenerative disease. Values of risk reduction may also be sensitive to the affected organ and environmental pathway. These results require confirmation and further refinement for use in policy analysis. 


\section{References}

Alberini, A., M. Cropper, A. Krupnick, and N.B. Simon. (2002) "Does the Value of a Statistical Life Vary with Age and Health Status? Evidence from the United States and Canada," Discussion Paper 02-19, Resources for the Future, Washington, D.C.

Arrow, K., R. Solow, P. Portney, E. Leamer, R. Radner, and H. Schuman. (1993)."Report of NOAA Panel on Contingent Valuation," Federal Register 58, 4601-4614.

Buzby, J., R. Ready, and J. Skees. (1995). "Contingent Valuation in Food Policy Analysis: A Case Study of a Pesticide-Residue Risk Reduction," Journal of Agricultural and Applied Economics 27, 613-625.

Corso, P.S., J.K. Hammitt, and J.D. Graham. (2001) "Valuing Mortality-Risk Reduction: Using Visual Aids to Improve the Validity of Contingent Valuation," Journal of Risk and Uncertainty 23,165-184.

Cropper, M.L, and P.R. Portney. (1990). "Discounting and the Evaluation of Lifesaving Programs," Journal of Risk and Uncertainty 3, 369-379.

Cropper, M.L., and F.G. Sussman. (1990). "Valuing Future Risks to Life," Journal of Environmental Economics and Management 19, 160-174.

Cropper, M.L., S.K. Ayded, and P.R. Portney. (1994). "Preferences for Life Saving Programs: How the Public Discounts Time and Age," Journal of Risk and Uncertainty 8, 243-265.

Dreyfus, M.K., and W.K. Viscusi. (1995) "Rates of Time Preference and Consumer Valuations of Automobile Safety and Fuel Efficiency," Journal of Law and Economics 38, 79-105.

Drèze, J. (1962). "L'Utilitè Sociale d'une Vie Humaine," Revue Française de Recherche Opèrationelle 6, 93-118.

Environmental Protection Agency. (1987). "Protection of Stratospheric Ozone," Federal Register 52, 47489-47523, December 14.

$\mathrm{Fu}$, Tsu.-Tan., Jin-Tan. Liu and James K. Hammitt, "Consumer Willingness to Pay for Low-Pesticide Fresh Produce in Taiwan," Journal of Agricultural Economics 50: 220-233, 1999.

Gerking, S., M. De Haan, and W. Schulze. (1988). "The Marginal Value of Job Safety: A Contingent Valuation Study," Journal of Risk and Uncertainty 1, 185-199.

Hammitt, James K. (2000a). "Valuing Mortality Risk: Theory and Practice," Environmental Science and Technology 34, 1396-1400.

Hammitt, James K., and John D. Graham (1999). "Willingness to Pay for Health Protection: Inadequate Sensitivity to Probability?" Journal of Risk and Uncertainty 18, 33-62. 
Hammitt, James.K. (2000b). "Evaluating Contingent Valuation of Environmental Health Risks: The Proportionality Test," Association of Environmental and Resource Economists Newsletter 20, 14-19. Reprinted in Stated Preference: What Do We Know? Where Do We Go? (Proceedings). Report number EE-0436, U.S. Environmental Protection Agency, October.

Hanemann, W.M., J. Loomis, and B. Kanninen (1991) "Statistical Efficiency of DoubleBounded Dichotomous Choice Contingent Valuation," American Journal of Agricultural Economics 73, 1255-1261.

Hersch, J., and T.S. Pickton (1995). "Risk-Taking Activities and Heterogeneity of JobRisk Tradeoffs," Journal of Risk and Uncertainty 11, 205-217.

Hersch, J., and W.K. Viscusi (1990) "Cigarette Smokers, Seatbelt Use, and Differences in Wage-Risk Tradeoffs," Journal of Human Resources 25, 202-227.

Horowitz, J., and R.T. Carson. (1990) “Discounting Statistical Lives,” Journal of Risk and Uncertainty 3, 403-413.

Johannesson, M., P-O Johansson, and K-G Lofgren. (1997). "On the Value of Changes in Life Expectancy: Blips Versus Parametric Changes," Journal of Risk and Uncertainty 15, 221-239.

Jones-Lee, M. (1974). "The Value of Changes in the Probability of Death or Injury," Journal of Political Economy 82, 835-849.

Jones-Lee, M.W., M. Hammerton, and P.R. Philips. (1985). "The Value of Safety: Results of a National Sample Survey," The Economic Journal 95, 49-72.

Kimball, M.S. (1990) "Precautionary Saving in the Small and in the Large," Econometrica 58, 53-73.

Krupnick, A., A. Alberini, M. Cropper, N. Simon, B. O’Brien, R. Goeree, and M. Heintzelman. (2002) "Age, Health and the Willingness to Pay for Mortality Risk Reductions: A Contingent Valuation Survey of Ontario Residents," Journal of Risk and Uncertainty 24, 161-186.

Lee, S.J., P.J. Neumann, W.H. Churchill, M.E. Cannon, M.C. Weinstein, and M. Johannesson. (1997). "Patients' Willingness to Pay for Autologous Blood Donation," Health Policy 40, 1-12.

Liu, Jin-Tan and James K. Hammitt (1999) "Perceived Risk and Value of Workplace Safety in a Developing Country," Journal of Risk Research 2, 263-275.

Liu, Jin-Tan, James K. Hammitt, and Jin-Long Liu. (1997). "Estimated Hedonic Wage Function and Value of Life in a Developing Country," Economics Letters 57, 353-358.

Magat, W.A., W. Kip Viscusi, and J. Huber. (1996). “A Reference Lottery Metric for Valuing Health,” Management Science 42, 1118-1130.

McDaniels, T.L., M.S. Kamlet, and G.W. Fischer. (1992). "Risk Perception and the Value of Safety," Risk Analysis 12, 495-503. 
Mendeloff, J.M., and R.M. Kaplan. (1989). “Are Large Differences in 'Lifesaving' Costs Justified? A Psychometric Study of the Relative Value Placed on Preventing Deaths," Risk Analysis 9, 349-363.

Mitchell, R.C., and R.T. Carson. (1986). "Valuing Drinking Water Risk Reductions Using the Contingent Valuation Method: A Methodological Study of Risks from THM and Giardia," Resources for the Future, Washington, D.C.

Moore, M.J., and W.K. Viscusi. (1988) "The Quantity-Adjusted Value of Life," Economic Inquiry 26, 369-388.

Moore, M.J., and W.K. Viscusi. (1990a) "Discounting Environmental Health Risks: New Evidence and Policy Implications," Journal of Environmental Economics and Management 18, S51-S62.

Moore, M.J., and W.K. Viscusi. (1990b) "Models for Estimating Discount Rates for Long-Term Health Risks Using Labor Market Data," Journal of Risk and Uncertainty 3, 381-401.

Mrozek, J.R., and L.O. Taylor. (2002) "What Determines the Value of Life? A Meta Analysis," Journal of Policy Analysis and Management 21, 253-270.

National Center for Health Statistics. (1998). Health, United States, US Department of Health and Human Services, Hyattsville, Maryland.

Ng, Y.-K. (1992). “The Older the More Valuable: Divergence Between Utility and Dollar Values of Life as One Ages," Journal of Economics 55, 1-16.

Payne, J.W., D.A. Schkade, W.H. Desvousges, and C. Aultman. (2000). "Valuation of Multiple Environmental Programs," Journal of Risk and Uncertainty 21, 95-115.

Revesz, R.L. (1999). "Environmental Regulation, Cost-Benefit Analysis, and the Discounting of Human Lives," Columbia Law Review 99, 941-1017.

Rosen, S. (1988). “The Value of Changes in Life Expectancy," Journal of Risk and Uncertainty 1, 285-304..

Savage, I., (1993), “An Empirical Investigation into the Effect of Psychological Perceptions on the Willingness-to-Pay to Reduce Risk," Journal of Risk and Uncertainty 6, 75-90.

Schelling, T.C. (1968). "The Life You Save May Be Your Own," in S.B. Chase (ed.), Problems in Public Expenditure Analysis, Brookings, Washington, D.C.

Shepard, D.S., and R.J. Zeckhauser. (1984).“Survival versus Consumption,” Management Science 30, 423-439.

Smith, V.K., H. Kim, and D.H. Taylor. (2001) "Do the 'Near' Elderly Value Mortality Risks Differently?" presented at the Workshop on Assessing and Managing Environmental and Public Health Risks, Association of Environmental and Resource Economists, Bar Harbor, Maine. 
Subramanian, U., and M. Cropper. (2000). "Public Choices Between Life Saving Programs: The Tradeoff Between Qualitative Factors and Lives Saved," Journal of Risk and Uncertainty 21, 117-149.

Sunstein, C.R. (1997). "Bad Deaths," Journal of Risk and Uncertainty 14, 259-282..

Viscusi, W.K. (1993).“The Value of Risks to Life and Health,” Journal of Economic Literature 31, 1912-1946.

Viscusi, W.K., and J. Hersch. (2001). "Cigarette Smokers as Job Risk Takers," Review of Economics and Statistics 83, 269-280.

Viscusi, W.K., and J.E. Aldy. (2002). "The Value of a Statistical Life: A Critical Review of Market Estimates Throughout the World," John M. Olin Center for Law, Economics, and Business Discussion Paper No. 392, Harvard Law School, Cambridge.

Viscusi, W.K., and M.J. Moore. (1989) "Rates of Time Preference and Valuations of the Duration of Life," Journal of Public Economics 38, 297-317.

Weinstein, M.C., D.S. Shepard, and J.S. Pliskin. (1980).“The Economic Value of Changing Mortality Probabilities: A Decision-Theoretic Approach," Quarterly Journal of Economics 94, 373-396. 
Table 1. Variable names, definitions, and descriptive statistics

\begin{tabular}{llcc}
\hline Variable & Definition & Mean & (Std. Dev.) \\
\hline Cancer & 1 if the question is about cancer, 0 otherwise & 0.504 & $(0.500)$ \\
Liver & 1 if liver disease, 0 if lung disease & 0.500 & $(0.500)$ \\
Latent & 1 if disease is latent, 0 otherwise & 0.530 & $(0.499)$ \\
Risk magnitude & 1 if initial risk is high (8/100,000), 0 if low (2/100,000) & 0.497 & $(0.500)$ \\
Q1 & 1 if first question, 0 otherwise & 0.250 & $(0.433)$ \\
Q2 & 1 if second question, 0 otherwise & 0.250 & $(0.433)$ \\
Q3 & 1 if third question, 0 otherwise & 0.250 & $(0.433)$ \\
Household size & Number of people in household & 4.287 & $(1.758)$ \\
Age & Respondent's age in years & 39.09 & $(10.11)$ \\
Male & 1 if respondent is male, 0 if female & 0.555 & $(0.497)$ \\
Married & 1 if the respondent is married, 0 otherwise & 0.748 & $(0.434)$ \\
Ln(income) & Log of monthly income (NT\$, 1US\$= 34.5NT\$) & 10.62 & $(0.509)$ \\
College & 1 if the respondent has college degree, 0 otherwise & 0.238 & $(0.426)$ \\
Health & 1 if perceived health is excellent or very good, 0 otherwise & 0.593 & $(0.491)$ \\
Disease & 1 if respondent has respiratory disease, 0 otherwise & 0.163 & $(0.369)$ \\
Smoker & 1 if respondent is currently a smoker, 0 otherwise & 0.268 & $(0.443)$ \\
Seat belt & 1 if respondent regularly uses seat belt, 0 otherwise & 0.647 & $(0.478)$ \\
Air quality & Perceived air quality, from 0 (worst) to 10 (best) & 5.738 & $(2.130)$ \\
Water quality & Perceived drinking water quality, from 0 (worst) to 10 & 5.935 & $(2.034)$ \\
Taiwanese & (best) & & \\
Taipei city & 1 if ethnicicy is Taiwanese, 0 if Chinese & 0.834 & $(0.372)$ \\
Taipei county & 1 if respondent lives in Taipei city, 0 otherwise & 0.276 & $(0.447)$ \\
Taoyuan county lives in Taipei county, 0 otherwise & 0.321 & $(0.467)$ \\
Kaohsiung city & 1 if respondent lives in Taoyuan county, 0 otherwise & 0.168 & $(0.373)$ \\
& & 0.135 & $(0.341)$
\end{tabular}


Table 2. Regression results

\begin{tabular}{|c|c|c|c|}
\hline \multirow{2}{*}{$\frac{\text { Variable }}{\text { Constant }}$} & $(1)$ & $(2)$ & (3) \\
\hline & $\begin{array}{c}6.298 * * * \\
(0.170)\end{array}$ & $\begin{array}{c}6.064 * * * \\
(0.209)\end{array}$ & $\begin{array}{c}0.032 \\
(2.090)\end{array}$ \\
\hline Cancer & $\begin{array}{c}0.304 \\
(0.193)\end{array}$ & $\begin{array}{c}0.305 \\
(0.194)\end{array}$ & $\begin{array}{c}0.324 \\
(0.199)\end{array}$ \\
\hline Liver & $\begin{array}{c}-0.749^{* * *} \\
(0.194)\end{array}$ & $\begin{array}{c}-0.737 * * * \\
(0.195)\end{array}$ & $\begin{array}{c}-0.733^{* * * *} \\
(0.201)\end{array}$ \\
\hline Latent & $\begin{array}{c}-0.273^{*} \\
(0.163)\end{array}$ & $\begin{array}{c}-0.373^{* *} \\
(0.175)\end{array}$ & $\begin{array}{c}-0.302^{*} \\
(0.181)\end{array}$ \\
\hline Risk magnitude & $\begin{array}{c}0.510^{* *} \\
(0.163)\end{array}$ & $\begin{array}{c}0.524 * * \\
(0.162)\end{array}$ & $\begin{array}{c}0.519^{* * *} \\
(0.168)\end{array}$ \\
\hline Q1 & & $\begin{array}{l}0.506^{* * *} \\
(0.239)\end{array}$ & $\begin{array}{c}0.500 * * \\
(0.249)\end{array}$ \\
\hline Q2 & & $\begin{array}{c}0.317 \\
(0.224)\end{array}$ & $\begin{array}{c}0.300 \\
(0.232)\end{array}$ \\
\hline Q3 & & $\begin{array}{c}0.281 \\
(0.227)\end{array}$ & $\begin{array}{c}0.318 \\
(0.235)\end{array}$ \\
\hline Household size & & & $\begin{array}{c}0.024 \\
(0.049)\end{array}$ \\
\hline Age & & & $\begin{array}{c}-0.023^{* *} \\
(0.011)\end{array}$ \\
\hline Male & & & $\begin{array}{l}-0.163 \\
(0.194)\end{array}$ \\
\hline Married & & & $\begin{array}{l}-0.175 \\
(0.240)\end{array}$ \\
\hline Ln(income) & & & $\begin{array}{c}0.611^{* * *} \\
(0.199)\end{array}$ \\
\hline College & & & $\begin{array}{c}0.345 \\
(0.213)\end{array}$ \\
\hline Health & & & $\begin{array}{c}0.057 \\
(0.173)\end{array}$ \\
\hline Disease & & & $\begin{array}{l}-0.138 \\
(0.229)\end{array}$ \\
\hline Smoker & & & $\begin{array}{l}-0.214 \\
(0.211)\end{array}$ \\
\hline Seatbelt & & & $\begin{array}{c}0.010 \\
(0.189)\end{array}$ \\
\hline Air quality & & & $\begin{array}{c}0.066 \\
(0.042)\end{array}$ \\
\hline Water quality & & & $\begin{array}{c}0.000 \\
(0.042)\end{array}$ \\
\hline Taiwanese & & & $\begin{array}{c}0.173 \\
(0.219)\end{array}$ \\
\hline
\end{tabular}




\begin{tabular}{|c|c|c|c|}
\hline \multicolumn{3}{|l|}{ Taipei city } & $\begin{array}{l}-0.323 \\
(0.340)\end{array}$ \\
\hline \multicolumn{3}{|l|}{ Taipei county } & $\begin{array}{l}-0.172 \\
(0.321)\end{array}$ \\
\hline \multicolumn{3}{|l|}{ Taoyuan county } & $\begin{array}{c}0.175 \\
(0.356)\end{array}$ \\
\hline \multicolumn{3}{|l|}{ Kaohsiung city } & $\begin{array}{c}0.388 \\
(0.357)\end{array}$ \\
\hline Sigma & $\begin{array}{c}2.413 \\
(0.093)\end{array}$ & $\begin{array}{c}2.404 \\
(0.093)\end{array}$ & $\begin{array}{c}2.361 \\
(0.095)\end{array}$ \\
\hline Sample size & 1,222 & 1,222 & 1,128 \\
\hline Log likelihood & -1485.36 & -1482.98 & -1361.11 \\
\hline
\end{tabular}

Table 3. Estimated value per statistical life (million US\$)

\begin{tabular}{llllll}
\hline Disease type & Latency & Organ/pathway & $(1)$ & $(2)$ & $(3)$ \\
\hline Cancer & Latent & Lung & 1.6 & 1.5 & 1.6 \\
Cancer & Acute & Lung & 2.1 & 2.2 & 2.1 \\
Non-cancer & Latent & Lung & 1.2 & 1.1 & 1.1 \\
Non-cancer & Acute & Lung & 1.6 & 1.6 & 1.5 \\
Cancer & Latent & Liver & 0.8 & 0.7 & 0.7 \\
Cancer & Acute & Liver & 1.0 & 1.1 & 1.0 \\
Non-cancer & Latent & Liver & 0.6 & 0.5 & 0.5 \\
Non-cancer & Acute & Liver & 0.7 & 0.8 & 0.7 \\
\hline
\end{tabular}

Note: Estimates correspond to models in corresponding column of Table 2.

VSL calculated as the average of the values for the two risk-reduction magnitudes. 


\section{Appendix: Survey Questions}

\section{Liver disease / water pathway}

As you know, the drinking water that is piped to your home is treated to remove microbial and chemical contaminants. However, there is always a risk that some contaminants may be present in the water.

Consider what you would do if you learned that there is a contaminant in the water supplied to your home that may cause [liver cancer / liver failure]. You and other people in your household can be exposed to the contaminant by drinking the water, and also by using it for bathing. The chance that you or someone in your household will be exposed to enough of this contaminant to cause [liver cancer / liver failure] is [2/8] chances in 100,000 per year.

Insert [Acute] or [Latent] description:

[Acute] The type of [liver cancer / liver failure] caused by this contaminant is always fatal. If someone in your household is exposed to enough of the contaminant to develop [liver cancer / liver failure], they will develop symptoms within a few months, and will live only about 2 to 3 years longer.

[Latent] The type of [liver cancer / liver failure] caused by this contaminant is always fatal, but it takes a long time to develop. If someone in your household is exposed to enough of the contaminant to develop [liver cancer / liver failure], they will not know it until they begin to experience symptoms about 20 years later. After developing these symptoms, they will live only about 2 to 3 years longer.

If someone in your household develops [liver cancer / liver failure], the symptoms will be mild at first. Eventually, they will become so weak that they will have to stay in bed or a wheel chair most of the time. They will not be able to take care of themselves. Once this occurs, they will die within one to two months.

The water-treatment plant can install additional treatment equipment to reduce the chance that the contaminant will be in your water. The treatment equipment is expensive, and the people who manage the plant are not sure if it is worth the cost. If the treatment equipment is installed, it will reduce the chance that someone in your household will be exposed to enough of the contaminant to develop [liver cancer / liver failure] from [2 / 8] chances in 100,000 per year to almost zero- to only 1 chance in 10 million per year.

If the plant installs the equipment, it will need to recover the cost by increasing the amount that consumers pay for their water. If the additional cost to your household would be NT\$ $[50,100,200,300,500]$ per month, would you want the plant to install the treatment equipment to reduce the chance that you or someone else in your household would develop [liver cancer / liver failure]? 


\section{Lung disease / air pathway}

Air pollution that is released from factories may cause [lung cancer / bronchitis]. Consider what you would do if you learned that the chance that someone in your household will be exposed to enough of this pollution to cause [lung cancer / bronchitis] is $[2 / 8]$ chances in 100,000 per year.

Insert [Acute] or [Latent] description:

[Acute] The type of [lung cancer / bronchitis] caused by this pollution is always fatal. If someone in your household is exposed to enough of the pollution to develop [lung cancer / bronchitis], they will develop symptoms within a few months, and will live only about 2 to 3 years longer.

[Latent] The type of [lung cancer / bronchitis] caused by this pollution is always fatal, but it takes a long time to develop. If someone in your household is exposed to enough of the pollution to develop [lung cancer / bronchitis], they will not know it until they begin to experience symptoms about 20 years later. After developing these symptoms, they will live only about 2 to 3 years longer.

If someone in your household develops [lung cancer / bronchitis], the symptoms will be mild at first. Eventually, they will become so weak that they will have to stay in bed or a wheel chair most of the time. They will not be able to take care of themselves. Once this occurs, they will die within one to two months.

The government can require factories to install additional air-pollution-control equipment to reduce the amount pollution coming out of the factory. The equipment will reduce the chance that someone in your household will be exposed to enough of the pollution to develop [lung cancer / bronchitis] from [2 / 8] chances in 100,000 per year to almost zero- to only 1 chance in 10 million per year.

If the government requires the factories to install this pollution-control equipment, it will increase the cost of many of the goods you buy. This would increase your cost of living. If the additional cost to your household would be NT\$ [50, 100, 200, 300, 500] per month, would you want the factories to install the pollution-control equipment to reduce the chance that you or someone else in your household would develop [lung cancer / bronchitis]? 
Table A-1. Survey design

\begin{tabular}{lll} 
Sub-sample & A1 & A2 \\
Question 1 & low risk, latent, liver cancer & high risk, acute, liver cancer \\
Question 2 & low risk, acute, liver cancer & high risk, latent, liver cancer \\
Question 3 & low risk, latent, bronchitis & high risk, latent, bronchitis \\
Question 4 & low risk, acute, bronchitis & high risk, acute, bronchitis \\
Sub-sample & A3 & A4 \\
Question 1 & low risk, latent, liver failure & high risk, latent, liver failure \\
Question 2 & low risk, acute, liver failure & high risk, acute, liver failure \\
Question 3 & low risk, acute, bronchitis & high risk, latent, bronchitis \\
Question 4 & low risk, latent, bronchitis & high risk, acute, bronchitis \\
Sub-sample & B1 & B2 \\
Question 1 & low risk, latent, lung cancer & high risk, acute, lung cancer \\
Question 2 & low risk, acute, lung cancer & high risk, latent, lung cancer \\
Question 3 & low risk, acute, liver cancer & high risk, latent, liver cancer \\
Question 4 & low risk, latent, liver cancer & high risk, acute, liver cancer \\
Sub-sample & B3 & B4 \\
Question 1 & low risk, latent, bronchitis & high risk, latent, bronchitis \\
Question 2 & low risk, acute, bronchitis & high risk, acute, bronchitis \\
Question 3 & low risk, acute, liver cancer & high risk, latent, liver cancer \\
Question 4 & low risk, latent, liver cancer & high risk, acute, liver cancer \\
\hline
\end{tabular}

Note: Describes the risk characteristics of the four questions asked to each of eight sub-samples of respondents. 